\title{
Observations on clausal complementation in Turkish Sign Language
}

Aslı Göksel and Meltem Kelepir

\begin{abstract}
The identification and structure of clausal complements in Turkish Sign Language (TID) is a hitherto uninvestigated topic in the literature. Based on a syntactic and prosodic analysis of the data (head-complement order restrictions, subject pronoun copy, Neg-raising, embedded question words with matrix scope, non-manual spreading, and others), we claim that clausal complementation exists in TID and show that complex clauses come in two forms: SOV structure is attested in clauses that involve a group of matrix verbs that we call want-type verbs, and (preferred) SVO order is seen with another group of verbs that we call know-type verbs. Our analysis of multiverb constructions as complex clauses is supported by a comparison between the prosody of independent clauses that form coordinated constructions and prosodic phenomena that point to syntactic dependency. The data comprise elicited clauses as well as grammaticality judgements of a total of 12 native signers. As this is the first study on complex clauses in TiD that we are aware of, we also discuss some methodological issues regarding the data that we base our analysis on and present the structural descriptions as tendencies rather than dichotomous facts.
\end{abstract}

\section{Introduction}

Various aspects of complex clauses in sign languages have been discussed in the literature. Among the relevant topics are whether complex clauses have overt complementizers or not (Liddell 1980; Neidle et al. 2000), the location of the complementizer in relative clauses (Petronio 1993), issues concerning simultaneity in the expression of complex clauses (Risler 2007), coordination (Napoli \& Sutton-Spence 2010), and other related issues (cf. Padden 1988; van Gijn 2004; Morgan \& Woll 2000; Sutton-Spence \& Woll 1999; 
Johnston \& Schembri 2007; among others). Concerning complexity in Turkish Sign Language (Türk Işaret Dili, TID), the only works that we are aware of are on relative clauses (Kubuş \& Rathmann 2011; Kubuş 2014).

In this paper, we identify two types of main verbs (want-type and knowtype verbs) that take clausal complements in TID. We base this distinction on the different orders these verbs take with respect to their clausal complements. These two verb types are known to differ in spoken languages in terms of the complement clauses they take. Such distinctions have been analyzed in relation to concepts such as factivity, referentiality, finiteness, control, etc. (Bošković 1997; Cinque 2001; Haegeman \& Ürögdi 2010; Giannakidou 2009; among many others). Since our present data do not allow us to identify the source of the difference of these complement clauses, we have chosen to refer to these two verb types with neutral, descriptive terms: want-type and know-type.

Based on various tests, we show that TiD has complex clauses and that these are distinct from coordinated clauses. Some of the tests we use have previously been discussed in the literature for sign languages but we also use other tests that we propose are indicators of complementation.

The structure of the paper is as follows: In Section 2, we provide some general information on TID users and explain how we collected our data. Section 3 addresses the syntactic and prosodic evidence that we have used to identify clausal complementation in TID. In Section 4, we discuss remaining issues relating to our main findings. Section 5 summarizes and concludes the paper and offers suggestions for further avenues for research.

\section{TíD users and data collection}

It is estimated that the deaf population in Turkey is around 300,000. It is unknown how many of these people are TiD signers. According to the Turkish Disability Survey (TDS 2002) quoted in Kemaloğlu \& Kemaloğlu (2012: 66-67), around sixty thousand of the deaf adults in Turkey "[...] prefer TiD in daily life communication; only less than $10 \%$ of them are used to speaking for communication in any occasion". The same authors note that the Turkish Disability Survey (TDS 2002) reports " $1 / 3$ of all people with hearing loss had speech and language disorders (SLDs). That is, in this survey, about 84,000 deaf citizens of the Turkish Republic are documented as "unable to hear and to speak'." The variation in the language and the level of competence of its users are unknown. The methods of assessing the numbers of the deaf population and the numbers of students in schools for the deaf are 
discussed in Kemaloğlu \& Kemaloğlu (2012). For further discussion of the history of the language and the Deaf community, see Zeshan $(2002,2003)$, Turgut \& Taşç1 (2011), and Taşç1 (2012).

The data presented in this paper were collected through a number of elicitation and grammaticality judgment tasks. A variety of tasks was conducted in three phases of the study and different groups of signers were involved in these tasks:

(i) Three deaf signers were asked to (a) repeat and, if necessary, correct the sentences of a TID-Turkish bilingual signer who is a CODA, (b) correct the signing of a beginner level (hearing) student of TID, and (c) provide grammaticality judgments on various sentences signed by the bilingual signer and the beginner level signer. All of the signers were born hearing to hearing parents but became deaf in infancy (before the age of three). Two are female, one is male, and they were between 37 and 48 years of age at the time of recording.

(ii) Two other signers were asked to read to themselves passages in Turkish consisting of two or three sentences on a slide on the computer screen. They looked away from the slide and signed what they remembered about the content of the passage.

(iii) The same two signers as the ones in (ii) were asked to read passages which served as the context for the test items to follow, written in Turkish on a slide on the computer screen. Afterwards, they were given ordered glosses of TiD signs and were asked to sign these ordered glosses as if they were sentences. These signers found some of the orders unacceptable and offered an order which they found acceptable. Later, seven different signers were asked to judge the signed sentences (including the ones that the first two signers found unacceptable). They were not given the contexts and thus judged the utterances in isolation. The informants gave grammaticality judgements for every sentence twice in random order.

\section{Evidence for clausal complementation in TiD}

The most obvious indication of clausal complementation one would look for in a sequence of clauses is the presence of complementizers. However, it is not very common for sign languages to have manual complementizers (Tang $\&$ Lau 2012). Thus, unsurprisingly, we have found no evidence of a manual complementizer in TID either. 
However, other phenomena may point to the existence of complementation. In the present study, we used some of the tests that have been offered in the literature as diagnostics for complementation in sign languages ((i) and (ii) below). In addition to these, we developed other tests that we list in (iii)-(vii).

(i) verb-complement order asymmetries (Section 3.1)

(ii) availability of a subject pronoun copy (Section 3.2)

(iii) negation (Section 3.3)

(iv) embedded question phrases taking matrix scope (Section 3.4)

(v) lexical non-manual marker spreading over the complement clause (Section 3.5)

(vi) a single prosodic marker spreading over the whole complex clause (Section 3.6)

(vii) absence of prosodic boundary markers of independent clauses and coordination at the complement clause boundary (Section 3.7)

Before we proceed, we would like to draw attention to some methodological points and certain challenges we faced while interpreting the data we gathered from our informants. We would like to stress that what we present in the following, especially in Sections 3.1 and 3.2, are simply some tendencies that we have observed in our data. This is due to the following two facts: (i) in some cases, grammaticality judgments of informants contradict what is found in the elicited data - such contradictions have been observed even for a single informant, and (ii) in some cases, there has been a large variation among the grammaticality judgments of informants, rendering the results inconclusive.

We believe such variation in a study on verb - clausal complement order may result from a number of factors: First, informants may vary in terms of their competence levels in TID and there is no standardized way of assessing TiD competence yet.

Second, word order properties of Turkish may have influenced the data. Bilingual informants may have inadvertently judged the given order as "acceptable" since the order complies with the order in Turkish. The risk of the influence of Turkish is present even in the elicited data, free or semifree. Note, however, that some word orders that are acceptable in Turkish were considered unacceptable in TID by some informants. Thus, the production and comprehension of this group can not have been totally affected by language contact in the case of these particular constructions. 
Third, different word orders in TiD may be possible depending on the information-structural functions of the constituents. Such variations are familiar from better-studied languages, especially those with scrambling. Thus, the inconsistencies among the signers' judgments are possibly due to the fact that one signer evaluated a sentence as an out-of-the blue sentence, while another assigned a different information-structural function to the sentence. This is, admittedly, a significant drawback of grammaticality judgment tasks in general.

Keeping these factors in mind, we present the tendencies that we observe in the data.

\title{
3.1. Verb-complement order asymmetries
}

In this section, we show that TiD verbs fall into two groups according to where their complements are and argue that this difference is an indication of clausal complexity. We focus on the main verbs listed in (1), as they are the most likely ones to take clausal complements. Please note that for KNOW and FORGET, we use two different glosses which are meant to reflect the different meanings these verbs have depending on their syntactic position; in both cases, the two variants have the same phonological form.

\author{
(1) THINK(IMAGINE) \\ THINK(GUESS) \\ COME.TO.MY.ATTENTION \\ UNDERSTAND \\ BE.SURE (DEFINITELY.KNOW) \\ WANT \\ MAKE.AN.EFFORT \\ LIKE \\ KNOW.HOW.TO \\ KNOW.THAT \\ FORGET.TO \\ FORGET.THAT \\ BELIEVE \\ WRITE
}

In our data, we observe a pattern concerning the type of the matrix verb and the position of clausal complements. One group of matrix verbs takes their clausal complements to their left, thus these structures are head-final, 
yielding $\mathrm{S}(\mathrm{O}) \mathrm{V}$ structures as predicted by studies on TID word order (Açan 2001; Sevinç 2006; Zeshan 2003, 2006; Kubuş 2008; Gökgöz 2009). For the other group of verbs, the preferred order is for their clausal complements to follow them, thus these constructions tend to be SVO. We call the former type want-type constructions and the latter know-type constructions.

\subsubsection{Want-type constructions}

We classify WANT, LIKE, KNOW.HOW.TO, FORGET.TO, and MAKE.AN.EFFORT under want-type verbs; informants show a strong preference for the SOV order with this type. Two representative examples are provided in (2) (where 'POSs' $=$ possessive).

(2) a. $\operatorname{ELA}_{\mathrm{k}} \mathrm{IX}_{\mathrm{k}}$ [GOOD SCHOOL GO] MUCH WANT

'Ela wants to go to a good school very much.'

b. $\left[\mathrm{IX}_{1 \mathrm{POSS}} \mathrm{SON}\right]_{\mathrm{k}} \mathrm{IX}_{\mathrm{k}}[\mathrm{SWIM}] \mathrm{MUCH}$ LIKE

'My son likes to swim/swimming very much.'

In the elicited data, we have not found a structure where a want-type verb occurs before its complement, and in 16 out of 19 presentations of such an order, informants found the structure unacceptable. In (3), we provide an example of a complex sentence with SVO order that was judged unacceptable.

\section{(3) ${ }^{*} \mathrm{ELA}_{\mathrm{k}} \mathrm{IX}_{\mathrm{k}}$ WANT [GOOD SCHOOL GO]}

The same restriction is observed in constructions where the embedded subject is different from the matrix subject. The sentences are grammatical when the matrix verb follows its complement, and ungrammatical otherwise, as is shown in (4).

(4) a. MELEK [CHILD GOOD SCHOOL GO] WANT

'Melek wants her child to go to a good school.'

b. *MELEK WANT [CHILD GOOD SCHOOL GO]

One might think, at first glance, that the reason for the ungrammaticality of (4b) arises from the separation of the main verb WANT from the embedded verb GO, under the assumption that these verbs may be forming 
a morphologically complex unit. However, this cannot be the source of the ungrammaticality. Head-initial order of the main verb is impossible even when the embedded verb occurs initially within its clause, that is, in cases where the two verbs are adjacent. In these cases SVO order is still ungrammatical, as shown in (5):

\section{* ELA $_{\mathrm{k}} \mathrm{IX}_{\mathrm{k}}$ WANT [GO GOOD SCHOOL]}

Intended: 'Ela wants to go to a good school.'

We conclude that the unmarked order between a want-type verb and its complement is OV.

\subsubsection{Know-type constructions}

Know-type verbs such as THINK, UNDERSTAND, BELIEVE, FORGET.THAT, and KNOW.THAT, in contrast to want-type verbs, display a less straightforward distribution in their order. A group of informants found only the VO order acceptable, as illustrated below.

(6) a. $\operatorname{ALI}_{\mathrm{k}} \mathrm{SELF}_{\mathrm{k}}$ THINK [AYŞE REST]

'Alı himself thinks Ayșe is resting.'

b. HASAN KNOW [ELIF HORSE.RIDE WORK SUCCEED WORK ++ SUCCEED]

'Hasan knows that Elıf is working on and succeeding at horseback riding.'

c. ${ }^{*} \mathrm{ALI}_{\mathrm{k}} \mathrm{SELF}_{\mathrm{k}}$ [AYŞE REST] THINK

It is noteworthy that the same group of informants found the OV order acceptable when the verb KNOW means "know how to". In this case, the order patterns with want-type verbs, indicating the lexical ambiguity of KNOW:

(7) $\left[\mathrm{IX}_{1 \text { POSS }}\right.$ SISTER $_{\mathrm{k}} \mathrm{IX}_{\mathrm{k}}$ [CAR DRIVE] KNOW.HOW.TO^NOT 'My sister does not know how to drive a car.'

Another group of informants, on the other hand, produced structures where the know-type main verb follows its complement, as shown for two different verbs in (8), thus contrasting with the judgements of the first group. 


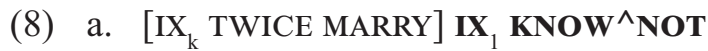

'I did not know that she got married twice.'

b. [IX $\mathrm{I}_{\mathrm{k}}$ LIE $] \mathbf{I X}_{1}$ UNDERSTAND

'I understood that he was lying.'

Note, however, that in cases as in (8) above where the main know-type verb follows its complement, a pronoun expressing the main subject usually occurs before the main verb. Crucially, the subject pronoun 'breaks up' the complement-verb adjacency, so to speak, giving rise to OSV order. Thus, these are not straightforward cases of OV structures. We will further discuss this pattern below.

\subsection{Subject pronoun copy}

The reference of subject pronoun copies has been used as a test to distinguish embedded clauses from coordinated clauses. For American Sign Language (ASL), it has been reported that when there is a pronoun at the end of what seems like a sequence of two clauses, one with a clausal complement taking verb, this pronoun can refer to the subject of the first clause (Padden 1988; Sandler \& Lillo-Martin 2006), shown in (9), where the sentence-final INDEX is co-referential with the matrix subject MOTHER. This is taken as an indication of embedding.

(9) MOTHER $_{i}\left[\text { SINCE }_{i} \text { PERSUADE }_{j} \text { SISTER }_{j} \text { COME }_{i}\right]_{i}$ INDEX $_{1}$

'My mother has been urging my sister to come and stay here, she [mother] has.'

(adapted from Sandler \& Lillo-Martin 2006: 299)

Such cases contrast with the following, a clear case of coordination, in which the (covert) subject of the first conjunct cannot be referred to by a sentencefinal subject pronoun copy.

${ }_{1}{ }_{1} \mathrm{HTT}_{i},{ }_{i}$ INDEX TATTLE MOTHER ${ }_{1}$ INDEX
'I hit him and he told his mother, I did.'

(Sandler \& Lillo-Martin 2006: 299)

The ungrammaticality of (10) has been argued to show that in contrast to clauses with complementation, as in (9), a clause-final subject pronoun cannot refer to the subject of the first conjunct in a sequence of coordinated clauses. Thus, the possibility of a subject pronoun copy appearing at the end of the clause has been taken to provide evidence for complementation. ${ }^{1}$ 
In TID, a subject pronoun co-referential with the matrix subject can occur at the end of want-type clauses:

(11) a. ALI $_{\mathrm{k}}\left[\mathrm{IX}_{1}\right.$ UNIVERSITY WORK $]$ WANT $\mathbf{I X}_{\mathrm{k}}$, 'AlI wants me to work at the university.'

b. PERHAPS I $\mathbf{X}_{\mathrm{k}}$ GROW-UP IX $\mathbf{x}_{\mathrm{k}}$ [SWIM] MUCH WANT $\mathbf{I} \mathbf{X}_{\mathrm{k}}$ 'He wants to swim very much perhaps when he grows up.'

c. $\left[\mathbf{I X} \mathbf{X}_{1 \text { POSS }} \text { SON }\right]_{\mathrm{k}} \mathbf{I \mathbf { X } _ { \mathrm { k } }}[\mathrm{SWIM}]$ MUCH LIKE $\mathbf{I} \mathbf{X}_{\mathrm{k}}$ 'My son likes to swim/swimming very much.'

In (11a) the embedded subject has disjoint reference from the matrix subject, while in the others these two are co-referential. ${ }^{2}$ As for a subject pronoun copy at the end of coordinated clauses, we would like to point out that our informants found structures comparable to (10) impossible to even articulate. These examples thus provide significant evidence that TID has embedded clauses.

In contrast to want-type constructions, right-peripheral pronominal copies of matrix subjects in know-type constructions, as in (12a), were unacceptable for our informants. ${ }^{3}$ Note that (12a) is a VO construction. As we mentioned in the previous section, know-type verbs can also appear after their complements. In these cases, a right-peripheral pronoun cannot refer to the matrix subject, as in (12b), either. There are also cases such as (12c), similar to (8) above, which at first sight might appear as instantiations of subject pronoun copies since there is a subject pronoun preceding the main verb and a non-pronominal noun phrase $\left(\mathrm{ALI}_{\mathrm{k}}\right)$ which the pronoun is co-indexed with. However, this subject pronoun is not in the canonical right-peripheral position, the position which provides the test; instead, it is between the main verb and its clausal complement. Thus, structures such as (8) and (12c) are not instances of subject pronoun copy constructions. ${ }^{4}$

(12) a. * ${ }^{*}$ HASAN $_{\mathrm{k}}$ KNOW [ELIF LESSON WORK] IX $\mathrm{k}_{\mathrm{k}}$

'Hasan knew Elif was studying.'

b. *?ALI IX $_{\mathrm{k}}\left[\mathrm{IX}_{1}\right.$ UNIVERSITY WORK $]$ KNOW IX $\mathbf{K}_{\mathrm{k}}$ Intended: 'Ali knows that I am working at the university.'

c. ALI $_{\mathrm{k}} \mathrm{IX}_{\mathrm{k}}\left[\mathrm{IX}_{1}\right.$ UNIVERSITY WORK $] \mathbf{I X}_{\mathrm{k}}$ KNOW

'AlI knows that I am working at the university.' 
(13) provides another example for the different distributions of want-type and know-type verbs. FORGET is lexically ambiguous between these two types of verbs. It can be interpreted as 'to forget to $\mathrm{x}$ ', or 'to forget that $\mathrm{x}$ '. The ambiguity correlates with different contexts:

(13) a. [HOUSE LEAVE STOVE TURN.OFF] FORGET.TO IX $_{\mathrm{k}}$ (as want-type) 'He forgot to turn off the stove when leaving the house.'

b. [IX ${ }_{1 \text { POSS }}$ FRIEND $]_{\mathrm{k}}$ TWO DAY AGO GERMANY GO. (as know-type) $\mathrm{IX}_{1}$ [pro $_{\mathrm{k}}$ GERMANY GO] IX $\mathrm{I}_{1}$ FORGET.THAT

'My friend went to Germany two days ago. I forgot that she went to Germany.'

Notice that (13a) parallels (11a) in that the main verb FORGET occurs after its clausal complement, and the subject pronoun copy is in the right-peripheral position. (13b), on the other hand, parallels (12c); there is a subject pronoun between the main verb FORGET and its clausal complement. We would like to suggest that the difference in the position of the pronoun is an illustration of the differences between want-type verbs and know-type verbs in TiD.

We surmise from the last two subsections that word order asymmetries indicate that the position of a complement with respect to its head is not random, and that selection of a complement is directional. ${ }^{6}$ The data also indicate that the consecutive expression of clauses does not necessarily give rise to coordination. If this were the case and the constructions were indeed coordinated, ordering restrictions would not be expected. We turn to this issue in Section 4.1.

\subsection{Negation}

In this section, we discuss two issues related to negation as an indicator of complementation. The first one concerns the spreading of the non-manual marker of main clause negation onto the complement clause, and the second one is related to the phenomenon known as Neg-raising.

\subsubsection{Spreading of the non-manual marker of negation}

It has been observed in some sign languages that a non-manual marker associated with main clause negation spreads over the complement clause (Padden 1988). We show below that TiD patterns with those languages. 
The most comprehensive work on negation in TIDD to date is Gökgöz (2011). In his study, Gökgöz concludes that among a number of non-manual markers related to the expression of negation, non-neutral brow position ('nbp' = browraising or brow-lowering) is the most frequent one in his data. ${ }^{7} \mathrm{He}$ reports that $71 \%$ of the negative utterances in his data are accompanied by this marker, adding that in $80 \%$ of these cases, it spreads over the entire sentence and in $20 \%$ of the cases only over the predicate. His interpretation of the spreading domain of 'nbp' is that it marks the c-command domain of the negative head.

This analysis predicts that if a negated verb takes a clausal complement, then 'nbp' is likely to spread over the complement as well. In other words, if 'nbp' marks the c-command domain of the higher negation and it spreads over a clause adjacent to the main verb, then one can conclude that this clause is actually in the c-command domain of the main verb, and hence, that it is the complement of this verb.

In our data, we have found cases where 'nbp' spreads over a predicate/ clause adjacent to another verb, indicating that these two clauses may be in a subordination relation. ${ }^{8}$ The following example illustrates this pattern.

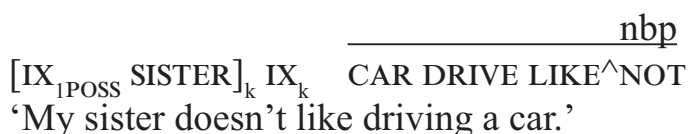

Here we observe regressive spreading of a feature from the sentence-final negated main verb LIKE.NOT onto the clause adjacent adjacent to its left. Crucially, the embedded verb DRIVE is not semantically negated. Moreover, there is no pause between DRIVE and LIKE ${ }^{\wedge}$ NOT. We therefore conclude that LIKE must be a clausal complement-taking verb.

\subsubsection{Neg-raising}

The second indication of complementation comes from the obligatoriness of Neg-raising in TID, which implies semantic unity between the main verb and its complement. In Neg-raising constructions, there is a mismatch between the semantics of the clause and the locus of the morphological realization of negation (cf. Horn 1995, among others). Neg-raising is a common phenomenon cross-linguistically, but it is limited to a few modal verbs, one of which is want, as in the English example in (15a) below:
a. I don't want [to go].
b. I want [not to go]. 
In (15a), even though negation is cliticized to the auxiliary do, what the speaker intends to express is a desire, and that desire is 'not to do something'. That is, s/he 'wants something', and that something is 'not going'. In such Neg-raising structures, the embedded verb has no marking for negation, however, it is interpreted as negative. Conversely, the main verb bears the negative marker even though it is not semantically negated. ${ }^{9}$ Thus, (15a) and (15b) are truth-conditionally equivalent. What (15a) actually expresses is $(15 b)$. Thus, semantic negation which is interpreted to be present in the embedded clause is realized morphologically in the higher clause. In other words, the negation associated with the embedded clause "raises" to the higher clause (i.e. morphologically appears in the higher clause). Naturally, this is only possible when one clause is embedded in the other, and it is not observed between two independent clauses.

The interpretation of negation in a clause it morphologically does not appear in is also impossible in coordinated clauses. Consider (16) below. Both examples contain the Neg-raising verb want; however, since these are instances of coordination and not complementation, Neg-raising is not possible. In other words, negation is clause-bound and the negation in one conjunct cannot be interpreted in the other.

a. [I want to leave $]$ and [not talk to him]. $\neq[$ I don't want to leave $]$ and [talk to him $]$.

b. [I talked to him] and [didn't want to leave]. $\neq$ [I didn't talk to him $]$ and [wanted to leave].

To summarize, the possibility of Neg-raising in a language can be taken as a diagnostic for complementation. Note that the lack of it is not sufficient to show that complementation does not exist, as in the case of e.g. knowtype verbs for which Neg-raising is ruled out for semantic reasons. In the following, we show that Neg-raising not only is possible, but obligatory with the verb WANT in TID.

It has been observed for TID that the non-manual lexical feature (dubbed (backward) head tilt, 'ht'), which is part of the morpheme for negation NOT spreads over the verb that is negated (cf. Zeshan 2006; Gökgöz 2009, $2011^{10}$ ).

Similar to the English example discussed above, in Neg-raising constructions in TID, although negation is semantically associated with the embedded clause (GET.UPSET in (17)), head tilt appears on the main verb (adapted from Gökgöz 2009) ('br' = brow raise). 


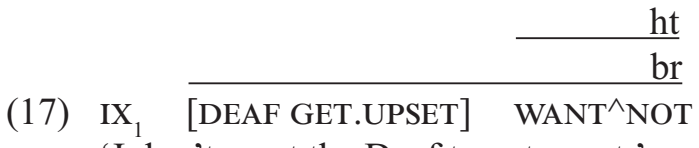
'I don't want the Deaf to get upset.'

Furthermore, note that the appearance of negation on the main verb is obligatory. If it occurs only on the embedded verb as in (18b), the structure is unacceptable (in the following examples, the only non-manual marker we indicate is head tilt).
ht
a. MELEK [TODAY FRIEND MEET] WANT $^{\wedge}$ NOT
'Melek doesn't want to meet her friends today.'
b. *MELEK [TODAY FRIEND $\frac{\text { ht }}{\text { MEET }^{\wedge} \text { NOT] WANT }}$

The possibility of Neg-raising in constructions like these suggests that the two propositions "Melek's meeting her friends today" and "Melek's not wanting this to happen" are neither expressed as syntactically independent clauses nor as syntactically coordinated clauses. The semantic unity observed here indicates that the verb WANT takes the other clause as its complement.

\subsection{Interpreting embedded question phrases with matrix scope}

Another sign of complexity is the possibility of interpreting a question word which is inside a complement clause with matrix scope, that is, as if it is in the matrix clause. It has been observed that this type of extraction out of embedded clauses is constrained in some sign languages. Van Gijn (2004), for instance, shows that in Sign Language of the Netherlands, extracting a question word out of the complements of some predicates such as 'want' and 'see' is possible whereas it is impossible to extract a question word from the complements of 'believe' and 'ask'.

In a language where question words are not obligatorily moved to a clause-peripheral position and/or where leaving them in-situ is preferred, extraction may not be a good testing tool. Instead, the possibility of interpreting an embedded question word with matrix scope and the spreading of question-related non-manual markers from the embedded clause onto the matrix clause would potentially be indicators of complexity. 
TiD allows wh-in-situ; other positions are also available for question words. However, there is no obligatory movement to a clause-peripheral position (cf. Makaroğlu 2012; Göksel \& Kelepir 2013). For the current study, we designed a task to test the existence of complex questions and the preferred word order in these constructions. Two signers were asked to produce questions based on a text given on the computer screen. First, they read a text in Turkish on a slide that introduced a context such as "You are in a grocery store, and you see a child crying. Ask her mother: ...". Then, on the next slide they saw glosses such as CHILD WHAT BUY WANT? Crucially, such glosses were in different orders on different slides and the informants were asked to sign a content question with TiD in the given order. The target data contained four types of complex questions, each with one of the main verbs WANT, GUESS, BELIEVE, and WRITE, and each type had four variants in terms of word order: (i) question word in-situ, (ii) question word in the right-peripheral position, (iii) question word in the left-peripheral position, and (iv) doubled question word: one copy of the question word in-situ, the other at the right-peripheral position. The task yielded a total of 16 sentences. The same two signers also volunteered to judge the different variations they themselves signed. Then, seven different informants gave grammaticality judgements for these utterances without seeing the written context. All nine informants uniformly accepted the in-situ cases, but there was variation in their evaluation of the other orders (one of which is presented in (22)). In (19) and (20), we provide two examples with question words in-situ.

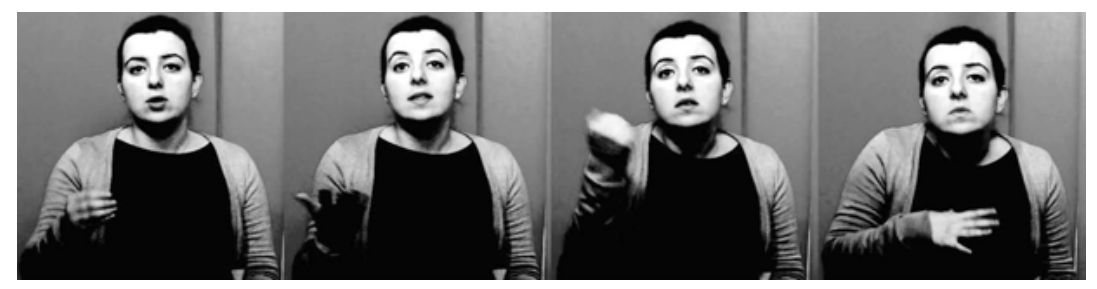

hs

$\mathrm{hb}$

br

CHILD

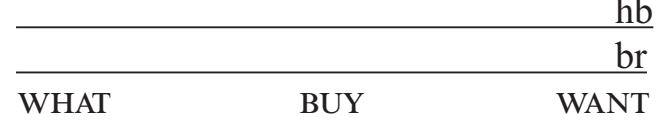

'What does the child want to buy?'

(20) $\mathrm{IX}_{2}$ WHO ELECTION WIN GUESS IX 'Who do you guess will win the election?' 
The fact that the constructions with the question word in-situ were consistently judged as acceptable, and were definitely interpreted as questions, shows that the embedded question word is interpreted as having matrix scope. This, in turn, indicates that the two clauses, the main clause and the clause that contains the question word, are in a subordination relation. This point is supported further by the spreading of the non-manual markers from the embedded clause to the matrix clause. In (19), the two non-manual markers of content questions reported in the literature, head backward and brow raise (see Makaroğlu 2012; Göksel \& Kelepir 2013), co-occur with the embedded question word WHAT, the embedded verb BUY, and, crucially, the matrix verb WANT.

\subsection{Spreading of a lexical non-manual marker over the complement clause}

We argued in Section 3.3 that the spreading of the non-manual marker of negation, a syntactic marker, onto the complement clause signals complementation. In this section, we discuss a similar phenomenon; however, in this case, a lexical non-manual marker of the main verb spreads over the complement clause, which we argue, is an indication of prosodic unity, and therefore, an indication of a verb - complement relation.

In a clause with a main verb like THINK(GUESS) (a know-type verb), the non-manual marker squint ('sq'), which seems to be a lexical feature of the verb, spreads over (part of) the complement clause. ${ }^{11,12}$ In our study, different informants preferred different orders between THINK(GUESS) and its complement. However, we observed that squint spreads over the complement regardless of the order. In the examples below, THINK(GUESS) precedes its clausal complement, and squint spreads from the main verb onto its complement. As can be observed in the examples in (21) and (22), the spreading domain of the non-manual marker is not necessarily the entire complement clause.

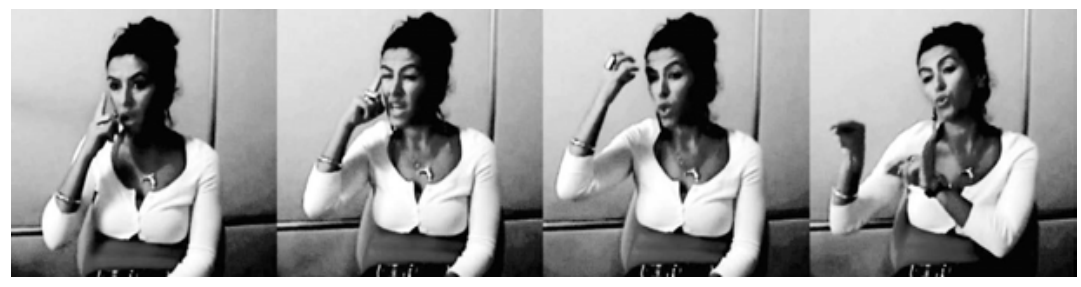

$\mathrm{sq}$

AYŞE THINK(GUESS) ÜLKÜ

SLEEP

'Ayşe thinks that Ülkü is sleeping.' 
In the following example, the main verb THINK(GUESS) follows its complement. Thus, squint spreads regressively onto the embedded verb WIN.

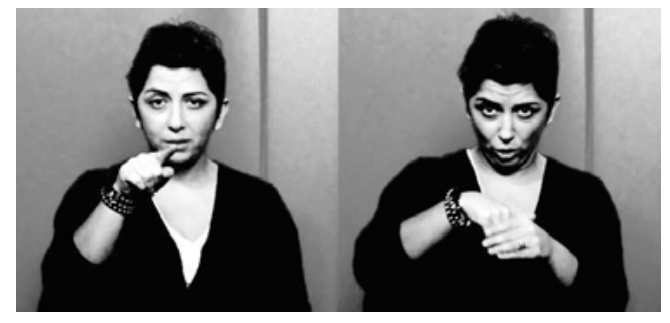

$\mathrm{IX}_{2}$

ELECTION

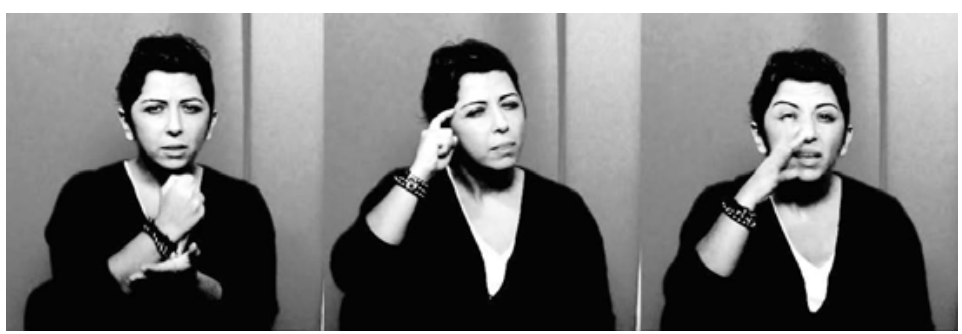

$\mathrm{sq}$

WIN THINK(GUESS) WHO

'Who do you think will win the elections?'

To conclude, progressive and regressive spreading of the lexical non-manual marker squint, associated with the verb THINK(GUESS), across the clausal boundary suggests that there is prosodic unity between the main verb and its complement, and thus, that these two belong to the same prosodic constituent. This, in turn, is likely to indicate that the two clauses are not syntactically independent of each other and that THINK(GUESS) is a clausal complementtaking verb.

\subsection{Static body posture on the whole complex clause}

We have observed that in complex clauses with clausal complements, the signers keep their body posture (head and torso) and body orientation constant throughout the entire complex clause. We call this static body posture ('sb'), and it is illustrated in (23). 
$\mathrm{sb}$

HASAN KNOW [ELIF HORSE.RIDE WORK SUCCEED WORK ++ SUCCEED] 'Hasan knows that Elif is working on and succeeding at horseback riding.'

We suggest that what we observe here is not simply the lack of a prosodic break at the left edge of the embedded clause, a point which we explore in the next subsection, but rather a non-manual marker marking the entire clause as a complex clause, similar to tunes in spoken languages. We return to this in more detail in Section 4.2. For now, suffice it to say that the fact that the signers we observed keep their body posture and body orientation constant throughout the entire complex clause shows that the two clauses form one prosodic constituent, which, taken together with the other pieces of evidence we presented, suggests that they are part of the same syntactic unit.

\subsection{Absence of prosodic boundary markers of independent clauses at the complement clause boundary}

There is a number of markers that have been discussed in the literature as marking Intonational Phrase (IP) boundaries. One of the pioneering works in this area is Wilbur (1994) on American Sign Language (ASL). Wilbur argues that ungoverned maximal projections in ASL form IPs. ${ }^{13}$ As discussed in Tang \& Lau (2012), possible non-manual markers aligning with IP boundaries are: (i) long pauses indicated by the lengthening of the final sign or hold (see also Nicodemus 2009), (ii) change in head position, (iii) acrossthe-board change of facial expressions, and (iv) change in brow posi$\operatorname{tion}^{14}$ (see also Sandler 1999). Moreover, one of the roles of certain types of eyeblinks in marking IP boundaries has been attested for various sign languages, including ASL (Wilbur 1994), Israeli Sign Language (Nespor \& Sandler 1999), German Sign Language (Herrmann 2010), Swiss German Sign Language (Boyes Braem 1999), and Hong Kong Sign Language (Tang \& Lau 2012). A common finding reported in these works is that the markers that are said to commonly occur at IP boundaries are not obligatory.

The same seems to apply to TID. The only study to have investigated non-manual markers as indicators of independent clauses in TID is Gökgöz \& Arrk (2011). In 96 single sentence utterances, they found the following manual (i, iv) and non-manual (ii, iii, v) markers occurring at the end of single sentences with the following frequencies: 
Table 1. Frequency of sentence-final (s-final) markers, from Gökgöz \& Arık (2011)

\begin{tabular}{ll}
\hline Marker & Frequency of s-final occurrence \\
\hline (i) hand-downs & $44 / 96$ \\
(ii) eye-blinks & $22 / 96$ \\
(iii) head-nods & $14 / 96$ \\
(iv) hand-holds & $10 / 96$ \\
(v) head-back & $4 / 96$ \\
\hline
\end{tabular}

Gökgöz \& Arık (2011) reach the conclusion that one or more of these markers is expected to occur at the end of an independent clause. These markers are similar to those observed for other sign languages discussed above, and here we assume that they can mark IP boundaries. The figures show that there is no dedicated non-manual marker that marks the right edge of an independent clause. $^{15}$

In our study, we nevertheless took these manual and non-manual markers as possible markers of IP boundaries, hence indicating the end of a proposition. Crucially, we saw none of these signs at complement clause boundaries. We then made a comparison of sequences of linked clauses, that is, coordinated clauses and complex clauses that contain subordinate clauses. ${ }^{16} \mathrm{We}$ observed that coordination in TID is marked by the following two signs:

(i) Lean backward ('lb') at the end of the final conjunct. This sign may be indicating completion or some kind of contrast with the previous utterance. It might be a marker similar to the head-back of Gökgöz and Arık (2011), or have a similar function to shrug in ASL, which means "that's all". 'Shrug' has been considered as a sub-type of lean backward (Wilbur \& Patschke 1998; Pfau \& Quer 2010).

(ii) Head thrust ('hth') at the end of the non-final conjunct, co-occurring with the final manual sign of the conjunct. This may be similar to the head nod of Gökgöz \& Arık (2011), and its function may more likely signal incompleteness, similar to those found in conditionals (Liddell 1986) and adverbial clauses (Wilbur 2000) in ASL. ${ }^{17}$ We provide two examples in (24).

hth

$\underline{\mathrm{lb}}$

(24) a. [[CHILD ${ }_{k}$ ALWAYS CANDY WANT] [IX ${ }_{3 \text { POSSa }}$ MOTHER ALWAYS GIVE] $]$ 'The child always wants candy, his mother always gives him candies.'

b. [[MELEK RUN MUCH $\frac{\text { hth }}{\text { LIKE] }]}$ [OZAN SWIM MUCH LIKE]]
'Melek likes running very much, Ozan likes swimming very much.' 
Assuming that head thrust is a prosodic boundary marker, it is no surprise that it marks the right edge of an IP in these examples. We observe that this marker does not occur between verbs and their clausal complements. ${ }^{18}$

We conclude this section by noting that in our database, we did not find a manual conjunction between coordinated sentences, although a manual marker AND (and maybe others) exists as a lexical item in TID. It might be that the manual marker AND is restricted to emphatic contexts, meaning "what's more", or there may be as yet undetected conjunctions as those discussed in Davidson (2013).

\subsection{Summary}

To summarize, we have presented evidence that clausal complementation exists in TID. A major body of support comes from non-manual markings. First of all, the main verb and its clausal complement form a prosodic constituent, as is evidenced by the following facts: (i) the structures we hypothesized to be complement clauses do not display prosodic boundary markers that have been observed for independent clauses or coordinated clauses, and (ii) the signer's body posture and orientation remains unchanged throughout the complex clause. Second, non-manual features which originate in the higher clause spread over the complement clause, which, from a syntactic point of view, is an indicator of clausal unity between a main clause and a syntactically dependent clause.

In addition to evidence from non-manual markings, we provided support for complexity in TID from a number of syntactic and semantic properties of the clauses we analyzed: (i) morpho-syntactic features originating in the embedded clause cross clause boundaries and either overtly occur in the main clause (Neg-raising), or are interpreted as having matrix scope (wide scope interpretation of embedded question phrases), (ii) a clause-final pronoun can be co-referential with the matrix subject across an intervening clause with want-type verbs, and finally, different verb types behave differently with respect to their complements, which shows that syntactic directionality is at play.

In the following section, we highlight some issues that have arisen as a consequence of our study. 


\section{Discussion}

In this section, we expand on the implications of two of our findings in more detail: the difference in the head-complement order of different verb types (Section 4.1) and the function of static body posture in clauses with clausal complements (Section 4.2).

\subsection{Head directionality and the structure of the complement}

We observed in Section 3.1 that there were two different types of verbs in terms of their respective orders vis-à-vis their clausal complements: wanttype verbs and know-type verbs. Want-type verbs follow their clausal complements and know-type verbs tend to precede their complements.

Why would this be the case? Can this be an outcome of the different types of syntactic relations that the two main verb types have with their clausal complements, and/or does it have to do with the syntactic size of the embedded clauses?

Similar observations on different complement-verb orders have been made for other sign languages (e.g. Italian Sign Language (LIS): Branchini (2007); Geraci, Cecchetto \& Zucchi (2008); Catalan Sign Language: Quer (2012)). In Geraci, Cecchetto \& Zucchi (2008) it is observed that verbs corresponding to what we call want-type verbs ("control verbs" in their terminology) follow their complements (as one would expect from an SOV language like LIS), while other clausal complements occur at the peripheries (OSV or SVO). They hypothesize that the difference between the two constructions is linked to the possibility that center embedding cannot be sustained by working memory. They propose that, in order to circumvent the effect on the working memory load, clausal complements of some other types of verbs are extraposed to a peripheral position, resulting in either an SVO or an OSV order. ${ }^{19}$ They further suggest that the reason why center embedding is not a problem for control verbs is that these predicates allow a strong degree of cohesion between the main and subordinate clause due to defective tense in the infinitival complement, even though there is no direct evidence for the lack of tense in complement clauses of control predicates in LIS. We have not found any direct evidence for the infinitival status of similar structures in TID either.

Another point Geraci, Cecchetto \& Zucchi (2008) bring up is the observation that complements of control verbs do not have overt subjects. The lack of an overt subject in complements of control verbs is claimed to yield 
a stronger degree of cohesion between the embedded and the main clauses. TID data suggest otherwise. The verb WANT in TID may have a complement with an overt subject (a noun or a pronoun) and it still follows its complement. The relevant examples in (4) are repeated in (25).

\section{a. MELEK [CHILD GOOD SCHOOL GO] WANT \\ 'Melek wants her child to go to a good school.' \\ b. *MELEK WANT [CHILD GOOD SCHOOL GO]}

In (25a), the complement clause has an overt subject, CHILD. In (26) and (27), we provide further examples with WANT and with MAKE.AN.EFFORT, respectively.

(26) $\left[\right.$ AYŞE $_{\mathrm{j}}$ HUSBAND $\left._{\mathrm{k}}\right] \mathrm{IX}_{\mathrm{k}}\left[\mathrm{AYŞE}_{\mathrm{j}} \mathrm{IX}_{\mathrm{j}} \mathrm{SATURDAY} \mathrm{WORK}\right]$ WANT $^{\wedge}$ NOT 'Ayşe's husband doesn't want Ayșe to work on Saturdays.'

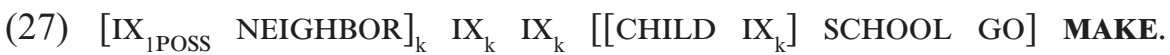
AN.EFFORT ${ }^{\wedge}$ NOT

'My neighbor does not try/make an effort for her child to go to school.'

In (26), the overt subject of the complement clause is AYŞE and in (27), it is CHILD. Crucially, in all these examples the main verb is sentence-final. Let us remind the reader that the idea of "morphological" cohesion is untenable as well, see the discussion on (5). We would also like to point out that if the claim that the unmarked word order in TID is $\mathrm{S}(\mathrm{O}) \mathrm{V}$ with a possibility of other orders is correct (Açan 2001; Sevinç 2006; Zeshan 2003; Kubuş 2008; Gökgöz 2009), then the puzzling cases are the know-type verbs since these tend to take their clausal complements after them, resulting in an SVO order. At present, we do not have an explanation for this pattern, but discuss various possibilities below.

To some extent, want-type verbs may seem to pattern with control verbs, and know-type verbs pattern with non-control verbs - similar to what has been suggested for LIS by Geraci, Cecchetto \& Zucchi (2008), as discussed above. As is well known, control verbs are those verbs that take a complement with an infinitival verb and a phonologically null subject. The phonologically null subject of the complement may either be co-referential with the main clause subject as in the English sentence " $\mathrm{I}_{\mathrm{i}}$ want [ $\mathrm{e}_{\mathrm{i}}$ to go there]", or with the object, as in "I persuaded him $_{\mathrm{i}}$ [ $\mathrm{e}_{\mathrm{i}}$ to go there]". In contrast, verbs such as know and think in English do not allow such clausal complements: "* $\mathrm{I}_{\mathrm{i}}$ knew $\mathrm{e}_{\mathrm{i}}$ to go there" or "* I knew him $\mathrm{e}_{\mathrm{i}}$ to go there" are ungrammatical. 
In the literature, various claims have been made to account for these differences. According to one of these, control verbs should be analyzed as monoclausal verbs (Cinque 2001). Another proposal is to replace the distinction based on the infinitival vs. tensed nature of the complements by a distinction based on the size of the complement (whether it has an overt complementizer or not; see Bošković (1997), and references therein). Yet other analyses focus on the referentiality and/or factivity of clausal complements, the status of complements as DPs or CPs, or the tense value of the embedded verb (Giannakidou 2009; Haegeman \& Ürögdi 2010; and references therein). At this stage, we have not been able to determine whether clausal complements in TID are distinguishable in terms of one of these factors. Thus, we cannot evaluate any of these highly interesting issues in the context of TiD.

\section{2. 'Static body posture': a tune that marks complexity?}

We showed in Section 3.6 that complex clauses involving complementation are consistently articulated with static body posture and orientation. One can raise the question whether this should be considered a distinct non-manual marker, or whether it simply shows the absence of a prosodic break.

It is true that the lack of any change in the non-manual articulators strongly indicates prosodic unity between the main verb and its clausal complement. However, we propose that in addition to the lack of a prosodic break, TiD may be employing a dedicated prosodic tune spreading over an entire clause, thus marking it as a prosodic constituent, possibly IP. This can be considered a case similar to non-manual marking of topics and questions (which are also generally considered IPs). If this is true, it would imply that at least one sign language, TID, marks clauses with clausal complements prosodically.

As far as we know, no such prosodic tune for complex clauses has been attested for spoken languages..$^{20}$ However, in at least one spoken language, Turkish, a similar tune has been argued to be part of question intonation. In Göksel, Kelepir \& Üntak (2010), we argue that Turkish question intonation consists of three parts, the first of which is a relatively flat tune with no peaks and valleys, which starts and continues at a pitch level higher than the average pitch level of the speaker. We further argue that it is this part of the contour that marks the utterance as an interrogative while the rest of the contour marks focus and distinguishes between different types of interrogatives. Functionally, this first part may be signalling to the hearer that the utterance which is being produced is an interrogative. 
In a similar vein, we would like to speculate that in a language like TID where inflectional marking is very scarce, static body posture of the signer may be signalling to the addressee that the utterance that is being produced contains complementation. In other words, static body posture throughout the clause may facilitate the interpretation of sequentially expressed complexity. It has been argued that the relative slowness of the manual articulators as well as constraints on short-term memory disfavour a system where information is expressed sequentially (Bellugi \& Fischer 1972; Aronoff, Meir \& Sandler 2005). Hence, marking the whole complex clause with a non-manual marker may function as a lynchpin that facilitates holding sequential information together.

\section{Conclusion}

This paper reports the results from a study which sought ways to find out whether clausal complementation exists in TiD. Our findings show that it does. In our search for this answer, we were able to identify several properties of constructions with complement clauses and properties of coordinated clauses.

We have found that in coordination, non-final conjuncts are marked by a head thrust at the right edge, while final conjuncts are marked by a lean backward. We suggested that head thrust may not be unique to conjuncts, but may be a general marker of incompleteness.

Regarding complement clauses, we identified two types of main predicates: want-type verbs and know-type verbs (another type are verbs of saying, which we discuss elsewhere, see Kelepir \& Göksel (2013)). The crucial observation is that clausal complements precede want-type verbs, as expected from an SOV language, while know-type verbs tend to be followed by their complements.

The major part of the evidence for the complement status of the clauses we analyzed came from non-manual markers. In particular, in the structures we investigated there is prosodic unity between the main verb and its complement. Furthermore, we identified a special non-manual marker, static body posture, and we speculated that this marker may constitute a tune that marks structures with clausal complementation. We also showed that nonmanual features of the higher clause can spread over the complement clause. Finally, we discussed Neg-raising structures and embedded question phrases with matrix scope as further evidence for complementation. 
One of the avenues for future research would be to identify the fine-grained differences between prosodic contours of clausal complements, replicating the experiments with larger participant groups. In addition, the investigation of the concept of finiteness, and related to this, infinitival constructions in sign languages, deserves further study. The investigation of complex clauses with other types of main verbs such as those taking embedded questions (see Hakgüder, 2015) will no doubt provide a more complete picture of complementation.

We hope that the present paper, which reports the findings of a limited study on an understudied sign language will contribute not only to sign language typology but also to our understanding of clausal complexity in general.

\section{Acknowledgements}

We would like to thank the audience at the workshop on "Complex Sentences and Beyond in Sign and Spoken Languages", 13-14 October 2011, Lichtenberg-Kolleg, Georg-August-Universität, Göttingen for their comments. We are grateful to our informants Miraç Bayhan, Mustafa Çil, Fikret Demirtaş, Büşra Dilsiz, Melihşah Gürbüzoğlu, Şule Kibar, Feride Korkmaz, Canan Metin, Abdullah Seçkin, Elvan Tamyürek Özparlak, and Gökhan Turgut, to our interpreters Nezihe Seyhan and Gül Yiğit, and to Emre Hakgüder, Derya Nuhbalaoğlu, Aslı Özkul, and Süleyman Sabri Taşçı for their technical assistance. We would also like to thank two anonymous reviewers and the editors of this volume who have helped us improve this paper. Needless to say, all remaining errors are ours. This research has been supported by Boğaziçi University Research Fund, BAP 5842 (11B04P1), TÜBİTAK Tidbil project (111K314), and has been conducted in the context of the COST Action SignGram (IS1006).

\section{Notes}

1. Note that some languages may not have this strategy, yet still have complementation; see Tang \& Lau (2012) and van Gijn (2004) for the disjoint reference of clause-final pronouns and main clause subjects in Hong Kong Sign Language and Sign Language of the Netherlands, respectively.

2. The acceptance rate of the structure in (11a) was 7 out of 8 (4 informants). $(11 b-c)$ are from elicited data. 
3. The acceptance rate for (12b) was 1 out of 8 (4 informants).

4. One obvious question regarding (12c) is what the status of $\mathrm{ALI}_{\mathrm{k}}$ is. These may be double topic constructions where the initial noun phrase and the clausal complement are both topics; however, since topics have not been investigated sufficiently in TID, we present this as a tentative possibility.

5. In English, too, forget is ambiguous. Consider the following examples where forget takes a non-finite complement in (ia), concomitant with the non-factive status of the embedded proposition, and a finite complement in (ib), where the embedded proposition is factive:

(i) a. He forgot to turn off the stove.

b. He forgot that I turned off the stove.

6. With the proviso that different word orders are also possible for informationstructural reasons.

7. Similar cases in our data appear as furrowed eye brows, however, we will use the term 'nbp' here for convenience.

8. As Gökgöz (2011) also notes, the non-manual marker for negation is not an obligatory marker in some sentences. Consistent with his report, we also observed it only in some of the negative sentences.

9. As stated, Neg-raising is not possible with all verbs. Consider (i) with the main verb know and (ii) with the main verb try. In contrast to (15a) and (15b), the (a)-sentences below are not truth-conditionally equivalent to the (b)-sentences.

(i) a. I didn't know that he went.

b. I knew that he didn't go.

(ii) a. I didn't try to go.

b. I tried not to go.

10. Zeshan (2006) describes this non-manual marker as head tilt, Gökgöz (2009, 2011) as (backward) head tilt. It appears to be a single movement of the head backwards.

11. Squint appears also in the citation form of this verb, which, we believe, indicates that it is a lexical feature. See Dachkovsky \& Sandler (2009:302f) for an analysis of the squint in ISL serving "[...] as a signal of the Low Accessibility status of the linguistic material it is aligned with". Squint in TID may be indicative of a similar function when the meaning of the verb is taken into consideration.

12. We do not have sufficient data to tell whether squint and/or its spreading are obligatory or not.

13. Wilbur (1994) observes that the syntactic correlates of IPs in ASL are main sentence CPs, topics/left dislocated constituents, and conditional clauses. See Wilbur (1994) for the discussion of other possible syntactic constituents forming IPs in ASL. 
14. It has also been observed that robust elements, fillers, morphologically heavy items, and focused items appear in IP-final position (cf. Nespor \& Sandler 1999; Wilbur 1999a, b; Brentari \& Crossley 2002).

15. The percentage of sentences that do not feature any of these markers may be larger as it is not clear how many of the sentences had more than one marker, and if so, with what percentage.

16. See the discussions on this topic in Thompson (1977), Liddell (1980), Padden (1988), Sandler \& Lillo-Martin (2006), Crasborn (2007), and Dixon (2008).

17. Note that Gökgöz \& Arık (2011) identify the marker head nod, a marker similar to what we describe as head thrust, as occurring at the end of a small percentage of independent clauses, as mentioned in Section 2. It is not clear from the description what discourse context head nod appears in their data. That is, it might be the very same sign we are describing as the marker for incompleteness and which may occur between the sentences of a single signer.

18. In addition to coordination and some cases of reported speech complements which we discuss elsewhere (Kelepir \& Göksel 2013), we expect head thrust to occur in listing and possibly at the right edge of adverbial clauses as well.

19. See Quer (2012) for an evaluation of this analysis.

20. Separate prosodic contours have been attested in embedded clauses in spoken languages (Ishihara 2003; Kawahara \& Takahito 2008; Richards 2010), but no such marking for the whole complex clause has been reported.

\section{References}

Açan, Ayça Zeynep. 2001. A study on sign languages and Turkish Sign Language. Unpublished MA dissertation, Hacettepe University, Ankara.

Aronoff, Mark, Irit Meir \& Wendy Sandler. 2005. The paradox of sign language morphology. Language 81(2). 301-344.

Bellugi, Ursula \& Susan Fischer. 1972. A comparison of sign language and spoken language. Cognition 1. 173-200.

Bošković, Željko. 1997. The syntax of nonfinite complementation. Cambridge: MIT Press.

Boyes Braem: Penny. 1999. Rhythmic temporal patterns in the signing of early and late learners of German Swiss Sign Language. Language and Speech 42(2/3). 177-208.

Branchini, Chiara. 2007. On relativization and clefting in Italian Sign Language (LIS). Ph.D dissertation, Università degli Studi di Urbino.

Brentari, Diane \& Laurinda Crossley. 2002. Prosody on the hands and the face, Evidence from American Sign Language. Sign Language \& Linguistics 5(2). $105-130$. 
Cinque, Guglielmo. 2001. 'Restructuring' and functional structure. University of Venice Working Papers in Linguistics, Vol. 11, 45-127.

Crasborn, Onno. 2007. How to recognize a sentence when you see one. Sign Language \& Linguistics 10(2). 103-111.

Dachkovsky, Svetlana \& Wendy Sandler. 2009. Visual intonation in the prosody of a sign language. Language and Speech 52(2-3). 287-314.

Davidson, Kathryn. 2013. 'And' or 'or': General use coordination in ASL. Semantics and Pragmatics 6(4). 1-44.

Dixon, Robert M.W. 2008. Complement clauses and complemetation strategies in typological perspective. In Robert M.W. Dixon \& Alexandra Y. Aikhenvald (eds.), Complementation: A cross-linguistics typology, 1-48. Oxford: Oxford University Press.

Geraci, Carlo, Carlo Cecchetto \& Sandro Zucchi. 2008. Sentential complementation in Italian Sign Language. In Michael Grosvald \& Dionne Soares (eds.), Proceedings of the $38^{\text {th }}$ Western Conference on Linguistics, 46-58. Davis, CA: California State University.

Giannakidou, Anastasia. 2009. The dependency of the subjunctive revisited: Temporal semantics and polarity. Lingua 119. 1883-1908.

Gijn, Ingeborg van. 2004. The quest for syntactic dependency: Sentential complementation in Sign Language of the Netherlands. PhD dissertation, University of Amsterdam. Utrecht: LOT.

Gökgöz, Kadir. 2009. Topics in Turkish Sign Language (Türk Işaret Dili - TID) syntax: Verb movement, negation, and clausal architecture. Unpublished MA dissertation. Boğaziçi University, Istanbul.

Gökgöz, Kadir. 2011. Negation in Turkish Sign Language: The syntax of nonmanual markers. Sign Language \& Linguistics 14(1). 49-75.

Gökgöz, Kadir \& Engin Arık. 2011. Distributional and syntactic characteristics of nonmanual markers in Turkish Sign Language (Türk İşaret Dili, TİD). MIT Working Papers in Linguistics 62: Proceedings of the $7^{\text {th }}$ Workshop on Altaic Formal Linguistics. 63-78.

Göksel, Aslı \& Meltem Kelepir. 2013. The phonological and semantic bifurcation of the functions of an articulator: HEAD in questions in Turkish Sign Language. Sign Language \& Linguistics 16(1). 1-30.

Göksel, Aslı, Meltem Kelepir \& Aslı Üntak-Tarhan. 2010. Decomposing the nonmanual tier: Cross-modality generalisations. In Iskoo Kwon, Hannah Pritchett \& Justin Spence (eds.), Proceedings of BLS-35, Special session on non-speech modalities, February 2009, 1-11.

Haegeman, Liliane \& Barbara Ürögdi. 2010. Referential CPs and DPs: An operator movement account. Theoretical Linguistics 36(2/3). 111-152.

Hakgüder, Emre. 2015. Complex Clauses with Embedded Constituent Interrogatives in Turkish Sign Language (TID). MA thesis, Boğaziçi University, Istanbul. 
Herrmann, Annika. 2010. The interaction of eye blinks and other prosodic cues in German Sign Language. Sign Language \& Linguistics 13(1). 3-39.

Horn, Laurence R. 1995. A natural history of negation. Chicago: Chicago University Press.

Ishihara, Shin. 2003. Intonation and interface conditions. PhD dissertation, MIT, Cambridge.

Johnston, Trevor \& Adam Schembri. 2007. Australian Sign Language; An introduction to sign language linguistics. Cambridge: Cambridge University Press.

Kawahara, Shigeto \& Shinya Takahito. 2008. The intonation of gapping and coordination in Japanese: Evidence for Intonational Phrase and Utterance. Phonetica 65. 62-105.

Kelepir, Meltem \& Aslı Göksel. 2013. Aspects of reported utterances in Turkish Sign Language. In Engin Ar1k (ed.), Current directions in Turkish Sign Language research, 186-213. Newcastle-upon-Tyne: Cambridge Scholars Publishing.

Kemaloğlu, Yusuf K. \& Pınar Y. Kemaloğlu. 2012. Türkiye’de işitme kayıplarının ve işitme engelinin genel görünümü [The general state of hearing loss and hearing impairment in Turkey]. Türkiye Klinikleri J.E.N.T. - Special Topics 5(2). 65-76.

Kubuş, Okan. 2008. An analysis of Turkish Sign Language (TID). Phonology and morphology. MSc dissertation, ODTÜ, Ankara.

Kubuş, Okan. 2014. Relative clause constructions in Turkish Sign Language (TID). PhD dissertation, University of Hamburg.

Kubuş, Okan \& Christian Rathmann. 2011. Animacy in relative clause constructions in Turkish Sign Language. Paper presented at Formal and Experimental Advances in Sign Language Theory (FEAST), Venice, June 2011.

Liddell, Scott K. 1980. American Sign Language syntax. Berlin: Mouton.

Liddell, Scott, K. 1986. Head thrust in ASL conditional sentences. Sign Language Studies 52. 243-262.

Makaroğlu, Bahtiyar. 2012. Türk İşaret Dilinde soru: Kaş hareketlerinin dilsel çözümlemesi [Questions in Turkish Sign Language: A linguistics analysis of brow movement]. MA thesis, Ankara University.

Morgan, Gary \& Bencie Woll. 2000. The development of complex sentences in British Sign Language. In Bencie Woll \& Gary Morgan (eds.), Directions in sign language acquisition, 255-275. Amsterdam: John Benjamins.

Napoli, Donna Jo \& Rachel Sutton-Spence. 2010. Sign language humour, human singularities, and the origins of language. In Gaurav Mathur \& Donna Jo Napoli (eds.), Deaf around the world: The impact of language, 231-250. Oxford: Oxford University Press. 
Neidle, Carol, Judy Kegl, Dawn MacLaughlin, Benjamin Bahan \& Robert G. Lee. 2000. The syntax of American Sign Language: Functional categories and hierarchical structure. Cambridge, MA: MIT Press.

Nespor, Marina \& Wendy Sandler. 1999. Prosody in Israeli Sign Language. Language and Speech 42(2-3). 143-176.

Nicodemus, Brenda. 2009. Prosodic markers and utterance boundaries in American Sign Language interpretation. Washington, DC: Gallaudet University Press.

Petronio, Karen. 1993. Clause structure in American Sign Language. PhD dissertation, University of Washington.

Padden, Carol. 1988. Interaction of morphology and syntax in American Sign Language. New York: Garland.

Pfau, Roland \& Josep Quer. 2010. Nonmanuals: Their grammatical and prosodic roles. In Diane Brentari (ed.), Sign languages (Cambridge Language Surveys), 381-402. Cambridge: Cambridge University Press.

Quer, Josep. 2012. A modality-free account of the position of clausal arguments. Paper presented at Formal and Experimental Advances in Sign Language Theory (FEAST), Warsaw, June 2012.

Richards, Norvin. 2010. Uttering trees. Cambridge, MA: MIT Press.

Risler, Annie. 2007. A cognitive linguistic view of simultaneity in process signs in French Sign Language. In Myriam Vermeerbergen, Lorraine Leeson \& Onno Crasborn (eds.), Simultaneity in signed languages: Form and function, 73101. Amsterdam: John Benjamins.

Sandler, Wendy. 1999. The medium and the message: Prosodic interpretation of linguistic content in Israeli Sign Language. Sign Language \& Linguistics 2(2). 187-215.

Sandler, Wendy \& Diane Lillo-Martin. 2006. Sign language and linguistic universals. Cambridge: Cambridge University Press.

Sevinç, A. Müge. 2006. Grammatical relations and word order in Turkish Sign Language (TID). Unpublished MA dissertation, ODTÜ, Ankara.

Sutton-Spence, Rachel \& Bencie Woll. 1999. The linguistics of British Sign Language, An introduction. Cambridge: Cambridge University Press.

Tang, Gladys \& Prudence Lau. 2012. Coordination and subordination. In Pfau, Roland, Markus Steinbach \& Bencie Woll (eds.), Sign languages: An international handbook, 340-364. Berlin: De Gruyter Mouton.

Taşçı, Süleyman Sabri. 2012. Phonological and morphological aspects of lexicalized fingerspelling in Turkish Sign Language (TID). Unpublished MA thesis, Boğaziçi University, İstanbul.

TDS. 2002. Türkiye Özürlüler Araştırması (2002a). [Turkey Disability Survey]. Ankara: Başbakanlık DİE Publications (Publication No: 2913), DİE Press. 
Thompson, Henry. 1977. The lack of subordination in American Sign Language. In Lynn Friedman (ed.), On the other hand: New perspectives on American Sign Language, 181-195. New York: Academic Press.

Turgut, Kadir \& Süleyman S. Taşç1. 2011. A historical perspective on first deaf schools, education methods and deafness in Turkey: 1889-1960. Paper presented at SIGN5 (International Conference of Sign Language Users). Gazi University, Ankara, 23 October 2011.

Wilbur, Ronnie B. 1994. Eyeblinks and ASL phrase structure. Sign Language Studies 84. 221-240.

Wilbur, Ronnie B. 1999a. Stress in ASL phrase structure. Language and Speech 42(2-3). 229-250.

Wilbur, Ronnie B. 1999b. Metrical structure, morphological gaps, and possible grammaticalization in ASL. Sign Language \& Linguistics 2(2). 217-244.

Wilbur, Ronnie. 2000. Phonological and prosodic layering of non-manuals in American Sign Language. In Karen Emmorey \& Harlan Lane (eds.), The signs of language revisited: An anthology to honor Ursula Bellugi and Edward Klima, 215-244. Mahwah, NJ: Lawrence Erlbaum.

Wilbur, Ronnie B. \& Cynthia G. Patschke. 1998. Body leans and the marking of contrast in American Sign Language. Journal of Pragmatics 30. 275-303.

Zeshan, Ulrike. 2002. Sign language in Turkey: The story of a hidden language. Turkic Languages 6(2). 229-274.

Zeshan, Ulrike. 2003. Aspects of Türk İşaret Dili (Turkish Sign Language). Sign Language \& Linguistics 6(1). 43-75.

Zeshan, Ulrike. 2006. Negative and interrogative structures in Turkish Sign Language (TID). In Ulrike Zeshan (ed.), Interrogative and negative constructions in sign languages, 128-164. Nijmegen: Ishara Press. 